\title{
ENDIVIDAMENTO PÚBLICO: Uma Análise em duas Associações de Municípios Catarinenses ${ }^{1}$
}

\section{PUBLIC DEBT: An Analysis in two Associations of Municipalities of Catarinenses}

\section{ENDIVIDAMENTO PÚBLICO: Un Análisis en dos Asociaciones de Municipios Catarinenses}

\begin{abstract}
Marcio Roberto Piccoli, Mestre em Ciências Contábeis pela Fundação Regional de Blumenau - FURB. Endereço Profissional: Câmara Municipal de Vereadores de Joaçaba. Rua Tiradentes, 872, Centro, 89600000 - Joaçaba, SC - Brasil. Telefone: (49) 35272900
\end{abstract}

Fax: (49) 35272900. E-mail: marcio.piccoli@ unoesc.edu.br.

\begin{abstract}
Alessandra Jerszurki, graduanda em Ciências Contábeis pela Universidade do Oeste de Santa Catarina - Unoesc. Endereço Profissional: R. Getúlio Vargas, 2125, Joaçaba - SC, 89600-000. Telefone: (49) 3551-2000. E-mail: aleh.jerszurki@ gmail.com.
\end{abstract}

\begin{abstract}
RESUMO
As entidades públicas de uma forma geral têm por objetivo exercer seu papel social, mantendo a estrutura pública atendendo às necessidades de uma comunidade, como infraestrutura, saúde, educação e transportes. Também é dever do Estado, exercer uma administração financeira pública de qualidade que consiga demonstrar o equilíbrio em suas contas públicas, gastando e investindo menos do que se arrecada. Nesse sentido, a pesquisa tem por objetivo identificar as variáveis explicativas do aumento do endividamento público nos anos de 2011 a 2014 de duas associações de municípios do estado de Santa Catarina: AMFRI - Associação dos Municípios da Foz do Rio Itajaí, e a AMMOC - Associação dos Munícipios do Meio Oeste Catarinense. A pesquisa caracteriza-se como qualitativa/quantitativa a partir da aplicação de regressão linear múltipla utilizando-se do Software SPSS $^{\circledR} 21.0$, em que foram analisados os dados e informações retiradas dos portais eletrônicos dos municípios analisados. A pesquisa identificou que a variação do endividamento público dos municípios pesquisados tem forte relação com as variáveis: receita de capital, receita corrente, despesa de capital, despesa corrente, número de habitantes, número de funcionários comissionados e número de funcionários efetivos. A pesquisa concluiu ainda que mesmo as associações possuindo diferentes bases de economia e localização, as variáveis despesas correntes e de capital, e número de habitantes apresentaram relação positiva e significativa em relação ao endividamento público dos municípios.
\end{abstract}

Palavras-chave: Endividamento Público. Administração Financeira. Contas Públicas.

\section{ABSTRACT}

Public entities in general have the objective of exercising their social role, maintaining the public structure, meeting the needs of a community, such as infrastructure, health, education and transport. It is also incumbent upon this State to exercise a quality public financial

\footnotetext{
${ }^{1}$ Artigo submetido em 05/07/2017, revisado em 17/08/2017, aceito em 16/02/2018 e divulgado em 10/07/2018 pelo Editor João Carlos Hipólito Bernardes do Nascimento, após double blind review.
} 
administration that is able to demonstrate the balance in its public accounts, spending and investing less than what it collects. In this sense, the research aims to identify the explanatory variables of the increase in public debt in the years 2011 to 2014 of two associations of municipalities in the state of Santa Catarina: AMFRI - Association of Municipalities of Foz do Rio Itajaí, and AMMOC - Association dos Municipalities of the Midwest of Santa Catarina. The research is characterized as qualitative / quantitative from the application of multiple linear regression using SPSS® Software 21.0, in which the data and information extracted from the electronic portals of the analyzed municipalities were analyzed. The main results of the research were that the variation in public debt in the cities surveyed was strongly correlated with the following variables: capital income, current revenue, capital expenditure, current expenditure, number of inhabitants, number of commissioned employees and number of employees Effective. The research also concluded that even associations with different economic and location bases, the current and capital expenditure variables, and the number of inhabitants showed a positive and significant relation with the public indebtedness of the municipalities.

Keywords: Public Indebtedness. Financial management. Public Accounts.

\section{RESUMEN}

Las entidades públicas de una forma general tienen, por objetivo ejercer su papel social, manteniendo la estructura pública atendiendo a las necesidades de una comunidad, como infraestructura, salud, educación y transportes. A este Estado también corresponde ejercer una administración financiera pública de calidad que pueda demostrar el equilibrio en sus cuentas públicas, gastando e invirtiendo menos de lo que se recaiga. En este sentido, la investigación tiene por objetivo identificar las variables explicativas del aumento del endeudamiento público en los años 2011 a 2014 de dos asociaciones de municipios del estado de Santa Catarina: AMFRI - Asociación de los Municipios de Foz do Rio Itajaí, y la AMMOC - Municipios del Medio Oeste Catarinense. La investigación se caracteriza como cualitativa / cuantitativa a partir de la aplicación de regresión lineal múltiple utilizando el Software SPSS® 21.0, en que se analizaron los datos e informaciones retiradas de los portales electrónicos de los municipios analizados. La investigación tuvo como principales resultados, de que la variación del endeudamiento público de los municipios encuestados tiene fuerte relación con las variables: ingreso de capital, ingreso corriente, gasto de capital, gasto corriente, número de habitantes, número de empleados comisionados y número de empleados Los efectivos. La investigación concluyó, que incluso las asociaciones poseyendo diferentes bases de economía y localización, las variables gastos corrientes y de capital, y el número de habitantes presentaron una relación positiva y significativa en relación al endeudamiento público de los municipios.

Palabras clave: Endeudamiento Público. Administración Financiera. Cuentas públicas.

\section{INTRODUÇÃO}

história da administração pública no Brasil começa a ser desenhada a partir de
1824 com a Constituição do Império, com o intuito de fixação de despesas e
repartição da contribuição direta. Desde então as leis e as assembleias gerais vieram aperfeiçoando e consolidando o principal objetivo do serviço público: atender e satisfazer o bem comum, planejando e administrando os recursos oriundos de receitas correntes e de capital, aplicando na manutenção da estrutura da "máquina pública" e no retorno à sociedade. (ARAÚJO; ARRUDA; BARRETO, 2009).

A administração financeira pública nos remete ao equilíbrio entre receitas arrecadadas e a sua aplicação em despesas relacionadas à estrutura do órgão público e a satisfação das GєCont, v. 5, n. 1, Floriano-PI, Jan-Jun. 2018. 
necessidades sociais, como papel social do Estado, conforme art. 194 da Constituição Federal de 1988. O equilíbrio entre essas variáveis é um dos princípios, que segundo Araújo, Arruda e Barreto (2009), dão direcionamento a "[...] elaboração, execução e controle dos orçamentos públicos no Brasil".

A elaboração do orçamento, como afirmam Piscitelli e Timbó (2009), veio para constituir uma espécie de controle sobre as ações dos governantes, guiados por premissas e princípios. Mais do que isso, o orçamento vem explicitar a origem dos recursos e a sua aplicação, assim definidos como receitas e despesas (gastos públicos), respectivamente.

Com base em definições de Araújo, Cavalcante e Monteiro (2010), tem-se que o principal desafio para um gestor público em relação ao funcionamento da entidade pública, é o controle de seus gatos, o qual se apresenta como um dos temas mais importantes em finanças públicas, determinando a qualidade e o seu desempenho social econômico do seu governo. Em teoria, a arrecadação de recursos públicos deveria ser suficiente para saldar os seus gastos. Como princípio do equilíbrio, gasta-se o que relativamente tem-se em "caixa", no entanto, quando se excede as despesas em relação às receitas, chega-se a um déficit orçamentário e para tanto, o órgão público recorre à captação de recursos fora da esfera do estado, a chamada dívida pública (KOHAMA, 2014).

Quando se aborda o assunto dívida pública ou endividamento surgem questionamentos sobre os motivos que levaram o órgão público a captar recursos, já que o Brasil bate todos os anos recordes de arrecadação de tributos. Subentende-se que, se o órgão público tem a necessidade de captar mais recursos, as suas receitas não foram suficientes para quitar as despesas no período, ou seja, o resultado foi deficitário. Esse resultado, segundo Shikida et al (2008), é obtido através de uma fórmula que leva em consideração dados como gastos públicos não financeiros; arrecadação não financeira; taxa de juros nominal; e estoque de títulos públicos. O resultado desta fórmula resulta na necessidade de financiamento do órgão público, representado por déficit ou superávit.

Razzera (2010) aborda que o governo ao tentar resolver o problema de déficit no país, encontra no endividamento uma saída, porém destaca que a dívida pública trouxe obstáculos para o crescimento econômico, aliado a isso questiona o alto endividamento dos municípios catarinenses no período de 2003 a 2007, mesmo depois da descentralização dos municípios e de uma maior autonomia fiscal de 1988 para cá. Aliado ao crescente endividamento, Pereira (2002) afirma que há um descompasso entre receitas e despesas públicas. Para o autor, no caso da União, há a emissão de dinheiro para fazer frente às despesas, ou, no caso de qualquer dos entes, há a concessão de crédito por alguém. O endividamento é uma das formas de financiamento desse descompasso.

Semelhante a Pastore (1995), o qual analisou a inflação e o déficit público no Brasil, o qual identificou que a "dívida pública voltaria a ter um crescimento sustentável, mas não porque o governo teria controlado ou eliminado os déficits públicos e sim porque o regime monetário tornar-se-ia endógeno", em outras palavras o déficit seria financiado pelo sistema monetário.

Por outro lado, Araújo, Cavalcante e Monteiro (2010), ao analisar a importância do gasto público no crescimento econômico em 73 municípios do Ceará no período de 2002 a 2005, observaram que os gastos públicos e o crescimento econômico são relevantes, e “[...] podem contribuir significativamente para uma gestão e alocação eficiente dos recursos públicos". Nessa mesma linha de pensamento, Rocha e Giuberti (2007) afirmam que a distinção do gasto público auxilia no crescimento do país, dividindo-se os gastos em produtivo e improdutivo, ressaltando a importância do gasto relacionado aos investimentos. Percebe-se dessa forma, que alguns autores veem o endividamento como um obstáculo para o cenário público, em que outros por sua vez, veem como auxílio para esse crescimento.

Diante desta abordagem, busca-se com esse estudo responder o seguinte problema de pesquisa: Quais as variáveis explicativas do aumento do endividamento público dos anos de GєCont, v. 5, n. 1, Floriano-PI, Jan-Jun. 2018. 
2011 a 2014 de duas associações de municípios de Santa Catarina? Dessa forma, o estudo tem por objetivo identificar as variáveis explicativas do aumento do endividamento público dos anos de 2011 a 2014 de duas associações de municípios de Santa Catarina.

Parte-se do pressuposto de que os recursos captados, assim definidos como receita de capital, são utilizados na maioria das vezes para custear as despesas de investimento, e as receitas tributárias, consideradas correntes para custear os gastos de manutenção.

Busca-se entender e preencher uma lacuna de pesquisa em relação à real dependência do órgão público sobre os recursos que originam o endividamento, assim chamados de capital, desmembrando os gastos relacionados a custeio, para dessa forma identificar quais motivos impedem a administração de realizar os investimentos somente com seus recursos próprios, oriundos de tributos e de subvenções.

O estudo proporcionará uma melhor compreensão do endividamento público, evidenciando os principais gastos e sua relação com o retorno a sociedade, a fim de informar aos cidadãos a gestão dos recursos públicos. O resultado obtido contribuirá para a transparência econômica dos municípios pesquisados e preencherá uma lacuna de pesquisa, haja vista, não ter sido encontrado estudos similares.

\section{REFERENCIAL TEÓRICO}

Aborda-se nesta seção, o referencial teórico da pesquisa o qual dará sustentação ao assunto pesquisado. Serão apresentados conceitos e a importância da elaboração do orçamento público para a administração pública, a partir de suas determinações legais. Conceitos referentes a classificações de receita e despesa, assim como sua origem e aplicação, oportunizando um debate sobre a importância do endividamento no setor público.

\subsection{ORÇAMENTOPÚBLICO}

O Orçamento anual tem sua origem a partir da criação do Plano Plurianual - PPA - em que estão previstas as prioridades ou diretrizes do governo assim como as metas e objetivos da administração pública. O PPA tem sua vigência para quatro anos, e tem por objetivo, servir de base para a elaboração das Leis de Diretrizes Orçamentárias - LDO e a Lei Orçamentária Anual - LOA, ambas com vigência de um ano (BRASIL, 1988).

O orçamento é parte atuante e peça fundamental no planejamento das ações públicas, no qual se apresenta a previsão de receitas, fixação de despesas e ajustes fiscais, assim como o plano de metas fiscais. Esse processo tem por finalidade dispor ao órgão público o passo a passo a ser seguido durante o desempenho de suas atividades no que concerne a execução das receitas e despesas.

Dessa forma, o orçamento se pauta observando-se os princípios definidos pela Constituição Federal de 1988, que são: a) anualidade: o orçamento faz referência á um exercício social, ou seja, a um ano, o qual se inicia em primeiro de janeiro e se encerra em 31 de dezembro; b) especificação: entende-se que todas as receitas e despesas no orçamento precisam estar especificadas sem quaisquer deduções; c) exclusividade: o orçamento tem por finalidade apresentar somente informações de ordem orçamentária; d) legalidade: o orçamento terá sua origem a partir de uma Lei; e) publicidade: esses princípios buscam dar transparência aos interessados nas informações orçamentárias; f) unidade: o princípio da unidade, busca consolidar todas as receitas e despesas em um único orçamento; g) equilíbrio: busca-se com esse princípio, equilibrar os recursos captados(receitas) devendo estes serem suficientes para suprir as despesas, as quais são representadas como de custeio e de capital (BRASIL, 1988).

Com a criação da Lei 4.320/64, as entidades públicas passaram a desempenhar suas atividades com base em um plano de ação, em que se tem a partir do planejamento a discrição

GєCont, v. 5, n. 1, Floriano-PI, Jan-Jun. 2018. 
e a aplicação das receitas auferidas. Esse planejamento é caracterizado pelo orçamento público em que se tem como premissa que aquilo que não estiver previsto ou orçado não poderá ser realizado. O que se busca com isso, é o atingimento e a maximização do emprego do dinheiro público para que seja possível o atendimento às necessidades de uma população.

É durante o processo orçamentário que a entidade pública busca identificar as suas necessidades de aplicação de recursos, definindo as ações a serem tomadas e identificando quais recursos e em quais quantidades serão aplicados a fim de solucionar os problemas sociais.

No processo orçamentário, além do planejamento e da elaboração do orçamento, se fazem necessários o controle e avaliação constante dos resultados, a partir da gestão administrativa dos gestores públicos. Nesse sentido, Piscitelli e Timbó (2009), acreditam que o conceito de orçamento como avaliação e controle de metas por atividades e aplicações e programas de trabalho pode ser fundamental no acompanhamento do Orçamento-Programas.

De acordo com Koscianski (2003), o orçamento-programa precisa ser muito bem planejado e executado para que as ações dos governos sejam mais eficientes e contribuam de forma significativa com o crescimento econômico, social e político do país.

Nesse sentido, essa realidade nem sempre foi presente na Administração Pública. Antes da Constituição Federal de 1988, o intuito do orçamento era de apenas discriminar o que foi arrecado e as suas destinações, sem um controle prévio e sem metas a serem cumpridas (GIACOMONI, 1986). Como se percebe, na visão de Giacomoni (1986), o orçamento ao longo do tempo possui uma característica mais de proforma (cumprir a legislação vigente) do que simplesmente auxiliar os gestores na execução dos programas.

Com a evolução do orçamento, muda-se a visão da função principal do Estado. Segundo os artigos $6^{\circ}$ e $7^{\circ}$, do Decreto 200 de 25/02/1967, as ações governamentais devem ter como base os princípios de planejamento, coordenação, descentralização, delegação da competência e controle, os quais têm como objetivo o crescimento econômico, social e político do país.

Esse crescimento pode ser motivado pela gestão eficaz dos gastos públicos, em que se observa pela afirmação de Araújo e Cavalcante (2010), de que é a partir do gasto público, que "o governo manifesta as suas prioridades mediante a prestação de serviços públicos básicos e a realização de investimentos". Diante desta abordagem, tem-se que Rocha e Giuberti (2007) afirmam que para que a entidade pública cresça, se faz necessário destinar os recursos para gastos que possam contribuir com esse crescimento, como por exemplo, gastos relacionados a investimentos.

Sendo assim, é de fundamental importância que os cidadãos tenham conhecimento sobre os gastos públicos, sua origem ou classificação econômica, para que dessa forma, seja possível entender o efeito econômico da sua destinação, em que a partir desse contexto será possível melhorar o entendimento de quanto a entidade pública destina à manutenção da estrutura pública e de quanto efetivamente está sendo aplicado em benefício de uma população.

\subsection{RECEITA E DESPESA PÚBLICA}

Os recursos recebidos e as destinações públicas, conhecidos como receitas e despesas, são legalmente classificados em categorias econômicas: receitas e despesas correntes e de capital (BRASIL, 1964).

Consideram-se receitas correntes aquelas cujo recurso provém de arrecadação de tributos, como taxas, impostos, contribuições de melhorias e empréstimos compulsórios. Integram também esse grupo, as receitas patrimoniais e recursos financeiros oriundos de instituições públicas ou privadas destinados a atender as despesas correntes, enquadrando-se nessa categoria as transferências correntes, conforme art. 11 da Lei $\mathrm{n}^{\circ}$. 4.320/64.

Por outro lado, tem-se os recursos financeiros provenientes de constituição de dívidas, captados em instituições financeiras de direito público ou privado, destinados exclusivamente

GєCont, v. 5, n. 1, Floriano-PI, Jan-Jun. 2018. 
para atender despesas de capital (investimentos). Ainda como receitas de capital, pode-se enumerar as originadas de alienações de bens móveis e imóveis (BRASIL, 1964).

As despesas correntes são aquelas de manutenção da estrutura pública, subvenções sociais e econômicas, definidas como transferência de recursos, de caráter assistencial ou subsidio às instituições públicas e privadas. Já as despesas de capital, tidas como investimento são definidas conforme Capítulo III, art.12, $\S 4^{\circ}$ da Lei 4.320/64:

[...] as dotações para o planejamento e a execução de obras, inclusive as destinadas à aquisição de imóveis considerados necessários à realização destas últimas, bem como para os programas especiais de trabalho, aquisição de instalações, equipamentos e material permanente e constituição ou aumento do capital de empresas que não sejam de caráter comercial ou financeiro.

Como utilização das receitas correntes, as mesmas podem ser utilizadas para custear despesas correntes e despesas de capital, porém todo recurso oriundo de receita de capital só terá como destino outra despesa de capital, a partir dessa observação legal nota-se que todo recurso financeiro de capital, somente poderá ser utilizado como investimentos, não sendo possível sua utilização com despesas de manutenção do órgão público.

Ante a abordagem do que vem a ser receita e despesa para a administração pública, fica mais evidente o quão importante deve ser o seu planejamento e controle. A partir do orçamento programa, fixa-se a despesa e se prevê a receita a ser arrecadada, a fim de atingir as metas de governo. Assim como nas organizações privadas tem-se o chamado lucro, nas organizações públicas tem-se o superávit. A meta é definida no planejamento e cabe no seu controle verificação, se esta foi ou não atingida apontando as possíveis causas. (GIACOMONI, 1986).

A importância desse controle deve-se ao fato de que todo o recurso recebido e patrimônio criado, pertencem à população, cabendo aos gestores os esclarecimentos sobre os direcionamentos desses recursos, apresentando informações quantitativas, de quanto foi recebido e aplicado, bem como informações de cunho qualitativas, qual o motivo da sua aplicação.

O gasto público em qualquer esfera de governo pode estar associado ao baixo crescimento econômico e a má administração financeira nos casos em que apresentar déficit. Porém, são a partir da identificação dos gastos públicos que se podem visualizar os gastos com manutenção de estrutura e de investimento.

Em regra geral, o órgão público não consegue atender de imediato, as reivindicações da comunidade, principalmente as necessidades que envolvam investimento com alto valor agregado, como construções prediais e infraestrutura (obras relacionadas a atendimento hospitalar ou na área da educação). Para tanto a captação de recursos de capital é necessária e imprescindível para a realização de investimentos. Nesse sentido, o órgão público capta recursos de instituições financeiras assim como verbas na esfera estadual e/ou federal. Esses recursos são tratados contabilmente como dívida pública, os quais considera-se todos os "compromissos assumidos pelo governo e os respectivos juros" (KOHAMA, 2014).

Neste contexto, a partir da legislação aplicável, a dívida pública pode ser dividida em "fundada ou consolidada" e "flutuante ou administrativa não consolidada". O que difere cada uma é o prazo, segundo art. 98, da Lei Federal n 4.320/64, a dívida fundada atende aos compromissos superiores há doze meses, necessários para "atender a desequilíbrio orçamentário ou a financiamento de obras e serviços públicos”. Já a dívida flutuante atende os compromissos inferiores há doze meses, cujas receitas estejam previstas no orçamento (BRASIL, 2000).

A partir da vigência da Lei de Responsabilidade Fiscal, alguns direcionadores foram impostos a gestão dos recursos públicos, pelo fato de que historicamente termos indícios de má gestão, com desequilíbrio de contas orçamentárias, alto endividamento e aumento de gastos

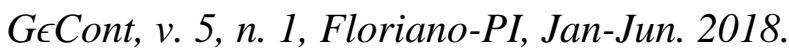


públicos. Para Carrasqueira (2006) a LRF significou um choque de moralidade na gestão pública, buscando a responsabilização em caso de má gestão e a conscientização de governos, políticos e sociedade da importância do bom trato da coisa pública. Nesse sentido para De Mello e Slomski (2009), após sua promulgação, o grau de endividamento das entidades públicas começa a diminuir.

Por outro lado, Versiani (2003), aponta, que mesmo após as definições de metas e limites ainda se fala em alto grau de endividamento em nível de Brasil e as possíveis causas são o aumento do gasto público em desequilíbrio com os recursos captados assim como a intervenção do estado na economia, como estratégia de, por exemplo, diminuição dos índices de inflação.

A partir da década de 1970, a livre interferência do meio econômico por parte do Estado, com atuação no mercado financeiro ou no controle de preços, aliado a fatores externos como a crise do petróleo, tem prejudicado o crescimento do país, em que as receitas não vêm acompanhando o aumento dos gastos, e a opção do governo para resolver o déficit é o endividamento (RAZZERA, 2010).

A partir da má gestão dos recursos públicos é que se tem um aumento do nível de endividamento das entidades. Para Rocha e Giuberti (2007) e Araújo, Monteiro e Cavalcante (2010), a análise do gasto público é fundamental e está relacionada com o crescimento econômico, à estrutura física, identificada como infraestrutura, os quais contribuem para o crescimento do Produto Interno Bruto (PIB) brasileiro, o que não é percebido em gastos administrativos de custeio.

De certa forma nota-se que o endividamento relacionado aos gastos com a estrutura e investimentos contribuem para o crescimento econômico, pois servem de insumo para o setor privado, melhorando o retorno do setor público a partir do pagamento de tributos. (CÂNDIDO JÚNIOR, 2009).

A seção 3 tem por objetivo apresentar os procedimentos metodológicos adotados na pesquisa, a fim de analisar o endividamento e os gastos públicos da amostra.

\section{PROCEDIMENTOS METODOLÓGICOS}

Quanto a abordagem a pesquisa classifica-se como qualitativa/quantitativa, pois além de possuir um objetivo com enfoque em dados e variáveis certas, busca-se analisar os fatos concretos, com hipóteses indutivas, procurando entender o impacto das variáveis encontradas (NEVES, 1996).

De acordo com Sá-Silva (2009) "a análise qualitativa do conteúdo começa com a ideia de processo, ou contexto social, e vê o autor como um autoconsciente que se dirige a um público em circunstâncias particulares". O autor vai além dos dados concretos, de certa forma, lê os números, e descreve o seu conteúdo simbólico a partir da escrita. Por outro lado, conforme aborda Gil (2010) a pesquisa quantitativa é aquela em que tudo pode ser quantificável, significa traduzir em números opiniões e informações para classificá-las e analisá-las, requerendo o uso de recursos e de técnicas estatísticas.

Quanto ao procedimento de pesquisa apresenta-se como documental. Para Marconi e Lakatos (2003) a característica da pesquisa documental é que a fonte de coleta de dados está restrita a documentos, escritos ou não, constituindo-se de fontes primárias e secundárias, as quais foram coletadas nos sites dos municípios, Tribunal de Contas de Santa Catarina e Banco Central do Brasil.

O estudo tem como objetivo analisar o endividamento de duas associações de municípios catarinenses, sendo uma da região litorânea de Santa Catarina e outra da região centro-oeste, conforme Tabela 1. A primeira motivação de escolha se deu pelo fato de as duas se assemelharem pelo número de municípios associados. A segunda motivação foi pelo fato de

GєCont, v. 5, n. 1, Floriano-PI, Jan-Jun. 2018. 
as duas associações se diferenciarem pela base de economia predominante, ou seja, em que a primeira possui um foco mais industrial enquanto a segunda predomina o agronegócio. A segunda motivação está pautada na justificativa de que se busca identificar, a partir de diferentes economias e regiões, semelhanças em relação ao endividamento público.

Tabela 1: Associações/Municípios pesquisados

\begin{tabular}{|l|l|}
\hline \multicolumn{1}{|c|}{ AMFRI (região litorânea) } & \multicolumn{1}{c|}{ AMMOC (região centro-oeste) } \\
\hline Balneário, Piçarras, Bombinhas, Camboriú, Ilhota, & Água Doce, Capinzal, Catanduvas, Erval Velho, \\
$\begin{array}{l}\text { Itajaí, Itapema, Luís Alves, Navegantes, Penha e } \\
\text { Porto Belo. }\end{array}$ & $\begin{array}{l}\text { Herval d'Oeste, Ibicaré, Joaçaba, Lacerdópolis, } \\
\text { Luzerna, Ouro, Tangará, Treze Tílias e Vargem } \\
\text { Bonita. }\end{array}$ \\
\hline
\end{tabular}

Fonte: Dados da Pesquisa.

Conforme Tabela 1, pertencem a AMFRI - Associação dos Municípios da Foz do Rio Itajaí, 11 municípios, enquanto a AMMOC - Associação dos Munícipios do Meio Oeste Catarinense é composta por 13 municípios, em que foram coletadas as variáveis identificadas a partir da Tabela 2.

Tabela 2: Variáveis da pesquisa

\begin{tabular}{|l|c|}
\hline \multicolumn{1}{|c|}{ Descrição da Variável } & Abreviatura da Variável \\
\hline Endividamento & END \\
\hline Despesas Correntes & DCOR \\
\hline Despesas de Capital & DCAP \\
\hline Receitas Correntes & RCOR \\
\hline Receitas de Capital & RCAP \\
\hline $\mathrm{N}^{\circ}$ de Funcionários Efetivos & FUEF \\
\hline $\mathrm{N}^{\circ}$ de Funcionários Comissionados & FUCOM \\
\hline $\mathrm{N}^{\circ}$ de Habitantes & NHAB \\
\hline
\end{tabular}

Fonte: Os Autores.

A partir da Tabela 2, a coleta de dados pode ser considerada como sendo de dados secundários, e se deu a partir de consultas aos sites dos municípios, Tribunal de Contas de Santa Catarina e Banco Central do Brasil, em que se buscou coletar as seguintes variáveis: endividamento, receitas e despesas (correntes e capital), número de habitantes, funcionários (efetivos e comissionados); a fim de poder identificar o impacto da dívida dos municípios, referente aos anos de 2011 a 2014.

Algumas variáveis não foram possíveis de serem coletas, haja vista, os municípios não dispor das mesmas em seus portais. Nesse sentido, no momento da regressão, por não apresentarem a variável Funcionários Efetivos (FUEF) referente ao ano de 2011, os Municípios de Itajaí, Camboriú, Luiz Alves, Catanduvas e Lacerdóplois foram excluídos. Já os municípios de Lacerdópolis, Erval Velho e Herval do Oeste, em função da falta dessa mesma variável nos anos de 2012 e 2013, também não participaram da regressão.

\section{ANÁLISE E INTERPRETAÇÃO DOS DADOS}

A fim de atender o objetivo da pesquisa, foi empregado como método estatístico de análise de dados, a Regressão Linear Múltipla e posteriormente a correlação de Pearson a fim de identificar a correlação entre as variáveis e explicar o endividamento dos municípios, utilizando-se para isso o Software SPSS $^{\circledR} 21.0$, em que se criou o modelo de regressão a partir das variáveis possíveis coletadas, o qual se apresenta a partir da Equação 01: 


$$
\begin{gathered}
\mathrm{END}=\beta 0+\beta 1 \mathrm{DCOR}+\beta 2 \mathrm{DCAP}+\beta 3 \mathrm{RCOR}+\beta 4 \mathrm{RCAP}+\beta 5 \mathrm{FUEF}+\beta 6 \mathrm{FUCOM}+ \\
\beta 7 \mathrm{NHAB}+\varepsilon \quad \text { Equação }(01)
\end{gathered}
$$

Nota-se, que a variável dependente é o endividamento e como variáveis independentes ou variáveis explicativas, as demais variáveis coletadas, identificadas pela Tabela 2, a fim de explicar um possível aumento de endividamento nos municípios pesquisados.

Diante da Equação proposta, foi realizado primeiramente os testes estatísticos, a fim de testar a independência dos dados e o poder explicativo do modelo de regressão proposto, conforme Tabela 3.

Tabela 1: Testes de independência dos dados

\begin{tabular}{lcccc}
\hline & 2011 & 2012 & 2013 & 2014 \\
\cline { 2 - 5 } Durbin Watson & 1,794 & 1,993 & 1,906 & 2,331 \\
$\mathrm{R}^{2}$ & 0,554 & 0,545 & 0,454 & 0,813 \\
$\mathrm{R}^{2}$ Ajustado & 0,346 & 0,332 & 0,395 & 0,726 \\
Observações & 23 & 23 & 23 & 23 \\
\hline
\end{tabular}

Fonte: Dados da pesquisa.

A partir da Tabela 3 nota-se que o teste Durbin-Watson, que tem por objetivo detectar a presença de auto correlação (dependência) entre as variáveis, indica que as variáveis analisadas não apresentam auto correlação, devido ao fato do indicador apresentar-se nos anos analisados, exceto o ano de $2011(1,794)$ próximo ou superior ou superior a 2

Quando analisado o $\mathrm{R}^{2}$ e o $\mathrm{R}^{2}$ ajustado, a Tabela 3 indica que o modelo de regressão proposto consegue explicar o endividamento a partir das variáveis coletadas acima de $50 \%$, sendo que no ano de 2014 acima de $81 \%$, indicando um bom poder explicativo das variáveis independentes em relação ao endividamento a partir do modelo de regressão proposto.

Após essas observações, passa-se a descrever os resultados encontrados a partir da aplicação da correlação de Pearson, em que se realizaram duas correlações envolvendo todas as variáveis dos quatro anos analisados, uma para cada associação pesquisada. Optou-se por utilizar essas variáveis, devido a sua disponibilização pública e pelo resultado de sua utilização nos estudos de Ribeiro (2009); Guilhoto e Sesso Filho (2010). As correlações são apresentadas nas Tabelas 4 e 5.

\begin{tabular}{|c|c|c|c|c|c|c|c|c|}
\hline & END & DCOR & DCAP & RCOR & RCAP & FUEF & FCOM & NHAB \\
\hline END & 1 & & & & & & & \\
\hline DCOR & $0,742 * *$ & 1 & & & & & & \\
\hline DCAP & $0,617 * *$ & $0,543 * *$ & 1 & & & & & \\
\hline RCOR & $0,674 * *$ & $0,928 * *$ & $0,505^{* *}$ & 1 & & & & \\
\hline RCAP & $0,353^{*}$ & $0,428 * *$ & $0,444 * *$ & $0,306^{*}$ & 1 & & & \\
\hline FUEF & $0,733 * *$ & $0,842 * *$ & $0,613 * *$ & $0,874 * *$ & 0,167 & 1 & & \\
\hline FCOM & 0,325 & $0,509 * *$ & 0,281 & $0,450 * *$ & 0,134 & $0,436 * *$ & 1 & \\
\hline NHAB & $0,742 * *$ & $0,878 * *$ & $0,443 * *$ & $0,911 * *$ & $0,290^{*}$ & $0,825 * *$ & $0,326^{*}$ & 1 \\
\hline
\end{tabular}

Tabela 4: Correlação de Pearson AMMOC

** A correlação é significativa no nível 0,01. *A correlação é significativa no nível 0,05

Legenda: END: Endividamento; DCOR: Despesa Correte; DCAP: Despesa Capital; RCOR: Receita corrente; RCAP: Receita Capital; FUEF: $N^{\circ}$ de funcionários efetivos; FCOM: $\mathrm{N}^{\circ}$ de funcionários comissionados; NHAB: $\mathrm{N}^{\mathrm{o}}$ de habitantes.

Fonte: Dados da pesquisa 
A primeira percepção que se obteve foi à relação positiva da maioria das variáveis independentes nas duas associações. Observa-se em relação ao endividamento, que na região da AMMOC, segundo a Tabela 4, a única variável que não apresentam correlação significativa de 0,01 e 0,05 , em relação ao endividamento é a FCOM ( $\mathrm{n}^{\circ}$ de funcionários comissionados). Nesse sentido, observa-se pela Tabela 4, que a maioria das variáveis apresenta correlação, ou seja, influenciam e são influenciadas pela variável endividamento de forma positiva.

As variáveis cuja relação é maior, são DCOR (despesa corrente) e NHAB ( $\mathrm{n}^{\circ}$ de habitantes) com relação positiva de 0,742 nas duas variáveis, que se assemelha ao resultado do trabalho de Crozatti (2010) et al., em que os autores concluíram que os municípios maiores, em números de habitantes, "têm maior relação da Dívida Consolidada Líquida e da diferença Passivo Financeiro e Ativo Financeiro com a Receita Corrente Líquida. ”

A relação FUEF ( $n^{\circ}$ de funcionários efetivos) e END (endividamento), apresenta correlação de 0,733 , assim como a variável RCAP (receita de capital) em relação ao END (endividamento), 0,353. Tem-se com isso, que a medida que o número de funcionários ou a receita de capital aumenta, há probabilidade de aumento da dívida pública, em que se tem uma correlação significativa de 0,01 e 0,05 respectivamente.

Pode-se identificar ainda a partir dos resultados obtidos na Tabela 4, que a despesa corrente assim como as variáveis já mencionadas, possuem correlação positiva com o aumento do endividamento e com a variação da despesa de capital. Diante desta constatação, pode-se concluir que a medida que a despesa corrente aumenta, ou seja, despesas de custeio e manutenção da entidade pública, o órgão aumenta sua despesa de capital e seu endividamento, com a obtenção de financiamentos. A Tabela 5 a seguir tem por objetivo demonstrar as variáveis explicativas do endividamento da segunda Associação de Municípios analisada.

Tabela 5: Correlação de Pearson AMFRI

\begin{tabular}{l|l|l|l|l|l|l|l|l}
\hline & END & DCOR & DCAP & RCOR & RCAP & FUEF & FCOM & NHAB \\
\hline END & 1 & & & & & & & \\
DCOR & $0,685^{* *}$ & 1 & & & & & & \\
DCAP & $0,707^{* *}$ & $0,855^{* *}$ & 1 & & & & & \\
RCOR & 0,677 & $0,881^{* *}$ & $0,795^{* *}$ & 1 & & & & \\
RCAP & $0,705^{*}$ & $0,638^{* *}$ & $0,731^{* *}$ & $0,744^{* *}$ & 1 & & & \\
FUEF & $0,394^{*}$ & $0,777^{* *}$ & $0,741^{* *}$ & $0,920^{* *}$ & $0,628^{* *}$ & 1 & & \\
FCOM & $0,519^{* *}$ & $0,594^{* *}$ & $0,532^{* *}$ & $0,758^{* *}$ & $0,617^{* *}$ & $0,746^{* *}$ & 1 & \\
NHAB & $0,738^{* *}$ & $0,843^{* *}$ & $0,798^{* *}$ & $0,920^{* *}$ & $0,697^{* *}$ & $0,778^{* *}$ & $0,809^{* *}$ & 1 \\
\hline
\end{tabular}

** A correlação é significativa no nível 0,01* A correlação é significativa no nível 0,05

Legenda: END: Endividamento; DCOR: Despesa Correte; DCAP: Despesa Capital; RCOR: Receita

corrente; RCAP: Receita Capital; FUEF: $\mathrm{N}^{\circ}$ de funcionários efetivos; FCOM: $\mathrm{N}^{\circ}$ de funcionários comissionados; NHAB: $\mathrm{N}^{\mathrm{o}}$ de habitantes.

Fonte: Dados da pesquisa

Ao compararmos a Tabela 5, a qual apresenta o resultado da correlação de Pearson da AMFRI, diferente da AMMOC, em que se tinha a variável FCOM (funcionários comissionados), a variável RCOR (receita corrente) não apresentou correlação em relação à END (endividamento), o que nos permite inferir, que na AMFRI, entre as duas variáveis não sofrem e/ou não influenciam a outra.

Semelhante a AMMOC, a variável NHAB ( $n^{\circ}$ de habitantes) é a que possui maior relação, com o endividamento, indicando que quanto maior o número de habitante, maior é a probabilidade de aumentar o endividamento público. As demais variáveis que se destacaram em relação a variação do endividamento, foram a DCAP (despesa de capital), e a RCAP (receita de capital). 
Diferentemente do resultado identificado pela Tabela 4, o número de funcionários comissionados influenciam e são influenciados pelo endividamento público. Fato que nos traz a disparidade das duas associações quando, algumas variáveis se correlacionam enquanto em outras, devidos a fatores econômicos, como a base de economia, número de habitantes, podem não exercer relação. Percebe-se também quando observado a variável FUEF ( $n^{\circ}$ de funcionários efetivos) e a variação do endividamento. Enquanto na Associação da AMMOC (Tabela 4), essa relação é a que representa maior correlação significativa, na Associação da AMFRI (Tabela 5), é a que menos se correlaciona com o endividamento.

Ao passo que se tem nas entidades públicas, a receita corrente e a despesa corrente, identificou-se uma relação positiva e significativa destas variáveis tanto na AMMOC, quanto na AMFRI em relação a variação do endividamento. Essa relação também pode ser identificada na evolução exposta nas Tabelas 6 e 7, que demonstra que quanto mais o governo arrecada, mas ele gasta na manutenção de sua estrutura, pois as duas variáveis crescem de forma proporcional.

Tabela 6: Relação entre RCOR e DCOR AMFRI

\begin{tabular}{ccccc}
\hline Ano & Despesa Corrente & \% variação & Receita Corrente & \% variação \\
\hline 2011 & $513.062 .127,59$ & $100,00 \%$ & $1.153 .113 .652,17$ & $100,00 \%$ \\
\hline 2012 & $575.939 .135,57$ & $12,26 \%$ & $1.336 .149 .076,29$ & $15,87 \%$ \\
\hline 2013 & $662.915 .430,59$ & $15,10 \%$ & $1.519 .086 .046,61$ & $13,69 \%$ \\
\hline 2014 & $725.808 .861,14$ & $9,49 \%$ & $1.619 .478 .902,26$ & $6,61 \%$ \\
\hline
\end{tabular}

Fonte: Dados da pesquisa

Tabela 7: Relação entre RCOR e DCOR AMMOC

\begin{tabular}{ccccc}
\hline Ano & Despesa Corrente & \% variação & Receita Corrente & \% variação \\
\hline 2011 & $164.354 .350,22$ & $100,00 \%$ & $302.036 .882,59$ & $100,00 \%$ \\
\hline 2012 & $185.913 .722,82$ & $13,12 \%$ & $333.976 .281,61$ & $10,57 \%$ \\
\hline 2013 & $196.005 .907,56$ & $5,43 \%$ & $355.340 .761,03$ & $6,40 \%$ \\
\hline 2014 & $198.512 .411,02$ & $1,28 \%$ & $393.024 .613,89$ & $10,60 \%$ \\
\hline
\end{tabular}

Fonte: Dados da pesquisa

O aumento da despesa corrente pode ser explicado pelo aumento na contratação de funcionários, aumentando com isso também as despesas de manutenção das prefeituras a medida que há um aumento da população, fato este justificado ao analisarmos a Tabela 8 , em que nos anos de 2011 a 2014 a variação foi positiva nas variáveis, número de funcionários efetivos, comissionados e número de habitantes nas duas associações. A disparidade de variação na AMFRI deve-se ao fato de que em alguns municípios, não estava disponível as informações relativas aos anos de 2011, 2012 e 2013. 
Tabela 8: Variação AMFRI e AMMOC

\begin{tabular}{|c|c|c|c|c|c|}
\hline \multicolumn{6}{|c|}{ AMFRI } \\
\hline \multicolumn{2}{|c|}{ Funcionários efetivos } & \multicolumn{2}{|c|}{ Funcionários comissionados } & \multicolumn{2}{|c|}{$\mathrm{N}$ de habitantes } \\
\hline Variação 2011 à 2014 & $153,82 \%$ & Variação 2011 à 2014 & $146,54 \%$ & Variação 2011 à 2014 & $11,24 \%$ \\
\hline \multicolumn{6}{|c|}{ AMMOC } \\
\hline \multicolumn{2}{|c|}{ Funcionários efetivos } & \multicolumn{2}{|c|}{ Funcionários comissionados } & \multicolumn{2}{|c|}{$\mathrm{N}$ de habitantes } \\
\hline Variação 2011 à 2014 & $59,27 \%$ & Variação 2011 à 2014 & $50,00 \%$ & Variação 2011 à 2014 & $3,81 \%$ \\
\hline
\end{tabular}

Fonte: Dados da pesquisa

As informações apresentadas na Tabela 8, após a análise das Tabelas 4 e 5, em que se tem correlação positiva e significativa entre a RCAP (receita de capital) e DCOR (despesa corrente) (DCOR), nos faz refletir que a medida que se aumenta a arrecadação com tributos corrente, se tem aumento natural da despesa corrente, em que o Governo, quando mais gasta com estrutura (custeio e manutenção), mais se faz necessário a captação de recursos para investimento (receita de capital).

Além da regressão e da correlação das variáveis, levantou-se a evolução do endividamento nas duas associações, retirando de seus portais eletrônicos as informações do endividamento em 31/12 de cada ano analisado conforme Tabela 9.

Tabela 9: Endividamento

\begin{tabular}{ccc}
\hline Ano & $\begin{array}{c}\text { Endividamento } \\
\text { AMFRI }\end{array}$ & $\begin{array}{c}\text { Endividamento } \\
\text { AMMOC }\end{array}$ \\
\hline 2011 & $61.483 .963,20$ & $13.433 .449,73$ \\
\hline 2012 & $76.454 .615,11$ & $22.925 .544,98$ \\
\hline 2013 & $68.276 .726,77$ & $21.287 .888,92$ \\
\hline 2014 & $55.735 .862,69$ & $18.824 .230,40$ \\
\hline
\end{tabular}

Fonte: Dados da pesquisa

Como se percebe pela Tabela 9, na AMFRI, de 2011 a 2013, todos os anos tiveram aumento em seu endividamento, em que se percebe um aumento significativo no ano de 2012 em relação a 2011. Já no ano de 2014 os municípios dessa associação tiveram uma diminuição no saldo de suas dívidas. Quanto a região da AMMOC, observa-se que em relação ao ano de 2011, os demais anos todos tiveram aumento no endividamento, em que, de 2011 para 2014 esse aumento foi de mais de $40 \%$.

\section{CONSIDERAÇÕES FINAIS}

A pesquisa teve como objetivo identificar as possíveis variáveis explicativas da evolução do endividamento público. Da análise dos resultados, pode-se inicialmente concluir que, as variáveis receita de capital (RCAP), receita corrente (RCOR), despesa de capital (DCAP), despesa corrente (DCOR), número de habitantes (NHAB), número de funcionários comissionados (FCOM) e número de funcionários efetivos (FUEF), se relacionam com a 
variação do endividamento, podendo estas variáveis serem responsáveis pelo aumento ou diminuição do endividamento.

Visualiza-se nas associações, que mesmo sendo de regiões e de economias diferentes, algumas colocações se assemelham, como é o caso da relação das despesas correntes e de capital, e do número de habitantes em relação ao endividamento. Nas duas associações essas variáveis são correlacionadas com o endividamento de forma positiva e significativa.

Em relação as correlações entre o gasto com estrutura e a receita obtida para investimento de obras públicas, fica evidente que quando o governo aumenta seu gasto corrente ele compromete a receita tributária, tendo que recorrer a receita de capital para investimentos, como por exemplo obras públicas, aumentando assim a sua capacidade de endividamento.

Outro fator importante a ser analisado, é em relação ao gasto e a receita corrente. $\mathrm{O}$ governo mesmo arrecadando cada vez mais, está destinando esses recursos aos gastos improdutivos, ou seja, aqueles que não contribuem com o crescimento econômico, quando deveria destinar aos gastos relacionados, a infraestrutura, a qual se acredita estar mais relacionada ao crescimento tanto econômico quanto social.

Quanto ao problema de pesquisa, acredita-se ter sido respondido durante o decorrer do artigo, em que se conseguiu identificar as variáveis do endividamento das duas associações pesquisadas. Nesse sentido, com base dos dados pesquisados e analisados, percebe-se que a associação AMFRI e a AMMOC estão reduzindo seu endividamento, porém a AMMOC de forma menos significativa.

Apesar de ter-se identificado que o endividamento das duas associações não está aumentando, as variáveis de maior significância identificadas podem reverter esse resultado, ou seja, se medidas não forem tomadas para o emprego sadio e equilibrado dos recursos públicos o endividamento poderá se tornar um problema ainda maior no futuro.

Como limitação da pesquisa, cita-se a dificuldade na captação dos dados, que mesmo existindo Leis que obrigue as entidades públicas a serem transparentes com a informação, ainda há municípios que não apresentam de forma clara estas informações, considerando ainda aqueles que se quer a divulgam. Os resultados da pesquisa limitam-se somente a análise destas duas associações, não podendo ser generalizado aos demais municípios de Santa Catarina e

Brasil. Sugere-se para futuros trabalhos a continuidade dessa pesquisa em nível estadual, a fim de identificar o crescimento do endividamento dos estados brasileiros, bem como a possível utilização de outras variáveis explicativas.

\section{REFERÊNCIAS}

ARAÚJO, Inaldo da Paixão Santos; ARRÚDA, Daniel Gomes; BARRETO, Pedro Humberto Teixiera. O essencial da contabilidade pública. São Paulo: Saraiva. 2009.

ARAÚJO, Jair Andrade de; MONTEIRO, Vitor Borges; CAVALCANTE, Cristina Aragão. Influência dos gastos públicos no crescimento econômico dos Municípios do Ceará. 2010.Disponível em http://www.repositorio.ufc.br/ri/handle/riufc/5428. Acesso 10 jan. 2015.

BRASIL. Constituição: República Federativa do Brasil de 1988. Brasília, DF: Senado Federal, 1988.

BRASIL. DECRETO -LEI n. 200, de 25 de fevereiro de 1967. Diário Oficial da União, Brasília, DF, 27 fev. 1967. Disponível em: http://www010.dataprev.gov.br/sislex/paginas/24/1967/200.htm. Acesso 22 mar 2015.

BRASIL. LEI n. 4.320, de 17 de março de 1964. Diário Oficial da União, Brasília, DF, 23 mar. 1964.

GєCont, v. 5, n. 1, Floriano-PI, Jan-Jun. 2018. 
BRASIL. LEI COMPLEMENTAR N 101, DE 4 de maio de 2000. Diário Oficial da União, Brasília, DF, 05 mai. 2000.

CÂNDIDO JÚNIOR, José Oswaldo. Os gastos públicos no Brasil são produtivos? Planejamento e Políticas Públicas, n. 23, 2009.

CARVALHO, Lena Oliveira de; MEDEIROS, Otavio Ladeira de; SILVA, Anderson Caputo. DÍVIDA PÚBLICA: A Experiência Brasileira. Brasília, 2009.

CROZATTI, Jaime et al. Endividamento Municipal no Brasil Antes e Depois da Lei de Responsabilidade Fiscal: Uma Análise Por Região Geográfica e Por Faixa da População. 2010. Disponível em http://www.anpad.org.br/admin/pdf/enapg473.pdf. Acesso em 06 mai 2015.

DE ALMEIDA CARRASQUEIRA, Simone. Investimento das empresas estatais e endividamento público. 2006. Disponível em http://dominiopublico.mec.gov.br/download/teste/arqs/cp000820.pdf. Acesso em 10 jan 2015.

DE MELLO, Gilmar Ribeiro; SLOMSKI, Valmor. Fatores que influenciam o endividamento dos estados brasileiros. Revista de Contabilidade e Organizações, v. 3, n. 7, p. 78-92, 2009. GIACOMONI, James. Orçamento público. 2. ed. São Paulo: Atlas, 1986. 215 p.

GIL, A. C. Como elaborar projetos de pesquisa. 6. ed. São Paulo: Atlas, 2010.

GUILHOTO, Joaquim; SESSO FILHO, Umberto Antonio. Estimação da Matriz InsumoProduto Utilizando Dados Preliminares das Contas Nacionais: Aplicação e Análise de Indicadores Econômicos para o Brasil em 2005 (Using Data from the System of National Accounts to Estimate Input-Output Matrices: An Application Using Brazilian Data for 2005). 2010. Disponível em https://papers.ssrn.com/sol3/papers.cfm?abstract_id=1836495. Acesso em 28 ago. 2017.

KOHAMA, Heilio. Contabilidade Pública: Teoria e Prática. 14. ed. São Paulo: Atlas, 2014.

KOSCIANSKI, Rogério. O orçamento-programa como instrumento de planejamento e gerenciamento públicos. 2003. Disponível em:

https://repositorio.ufsc.br/handle/123456789/86497. Acesso em 18 mar. 2015.

NEVES, José Luis. Pesquisa qualitativa: características, usos e possibilidades. Caderno de pesquisas em administração, São Paulo, v. 1, n. 3, p. 2, 1996. Disponível em

http://www.dcoms.unisc.br/portal/upload/com_arquivo/pesquisa_qualitativa_caracteristicas_u sos_e_possibilidades.pdf. Acesso em 31 mar2015.

PASTORE, Affonso Celso. Déficit Público, a Sustentabilidade do Crescimento das Dívidas Interna e Externa, Senhoriagem e Inflação: Uma Análise do Regime Monetário Brasileiro. Brazilian Review of Econometrics, v. 14, n. 2, p. 177-234, 1995.

PEREIRA, César A. Guimarães. O endividamento público na Lei de Responsabilidade Fiscal. Revista Diálogo Jurídico, n. 10, 01/2002. Disponível em: 〈www.direitopublico.com.br〉. Acesso em: 21 mar 2015.

PISCITELLI, Roberto Bocaccio; TIMBÓ, Maria Zulene Farias. Contabilidade Pública: Uma abordagem da administração pública. 11. ed. São Paulo: Atlas, 2010.

RAZZERA, Vinicius. Endividamento público dos municípios catarinenses 2003 a $2007.96 \mathrm{f}$. Monografia (Graduação em Ciências Econômicas) - Universidade Comunitária da Região de Chapecó, Chapecó, 2010. 
RIBEIRO, C. do A. et al. Finanças pessoais: análise dos gastos e da propensão ao endividamento em estudantes de administração. Anais do SEMEAD-Seminários em Administração, 2009. Disponível em http://sistema.semead.com.br/12semead/resultado/trabalhosPDF/385.pdf. Acesso em 28 ago. 2017.

ROCHA, Fabiana; GIUBERTI, Ana Carolina. Composição do gasto público e crescimento econômico: uma avaliação macroeconômica da qualidade dos gastos dos Estados brasileiros. Economia Aplicada, v. 11, n. 4, p. 463-485, 2007.

SÁ-SILVA, Jackson Ronie; ALMEIDA, CD de; GUINDANI, Joel Felipe. Pesquisa documental: pistas teóricas e metodológicas. Revista Brasileira de História \& Ciências Sociais, v. 1, n. 1, p. 1-15, 2009. Disponível em http://redenep.unisc.br/portal/upload/com_arquivo/pesquisa_documental_pistas_teoricas_e_m etodologicas.pdf. Acesso em 31 mar 2015.

SHIKIDA, Cláudio Djissey; PAIVA, Ana Luiza Vieira; ARAUJO JÚNIOR, Ari Francisco de. Déficit nominal zero: uma avaliação crítica a partir do Modelo IS-MP. Planejamento e

Políticas Públicas, v. 1, n. 31, 2009.

VERSIANI, F.R. A dívida pública interna e sua trajetória recente. Texto para discussão, UNB, 2003. 